\title{
The changing epidemiology of cerebral palsy
}

\author{
Peter O D Pharoah, Mary Jane Platt, Theresa Cooke
}

\begin{abstract}
Aim-To determine the prevalence of cerebral palsy in a specific population.

Methods-Multiple sources of ascertainment were used to create and maintain a register of all cases of cerebral palsy born to mothers resident in the counties of Merseyside and Cheshire in the years 1966 to 1989 . Denominator data of infant births and deaths from 1966 to 1981 were obtained from statutory notifications made to health authorities and, for the period 1982-89, from statutory birth and death registrations. Over 1500 cases formed the database for the study.

Results-The prevalence of cerebral palsy has increased among all the low birthweight groups with, most recently, an increase in infants weighing $<1000 \mathrm{~g}$ at birth. Low birthweight infants now comprise about $50 \%$ of all cases of cerebral palsy; in the early years of the study they comprised about $32 \%$ of all cases. The proportion of cerebral palsy by clinical type has changed among low birthweight babies, with relatively fewer cases with diplegia and a concomitant increase in the proportion with hemiplegia. An increase in the severity of functional disability, determined by the proportion of children with severe learning, manual, and ambulatory disabilities, was also found.

Conclusions-The change in the epidemiology of cerebral palsy has implications for the aetiology of the condition, and for health, educational, and social service provision.

(Arch Dis Child 1996;75:F169-F173)
\end{abstract}

Keywords: cerebral palsy, prevalence, disability, trends.

The sharp rise in prevalence of cerebral palsy is directly proportional to decreasing birthweights, rising from about 1 per 1000 live births among infants weighing over $2500 \mathrm{~g}$ at birth to about 80 per 1000 in infants weighing $1500 \mathrm{~g}$ or less at birth. ${ }^{1-3}$ Since the $1960 \mathrm{~s}$, there has been a striking improvement in the survival of infants of low birthweight ${ }^{4-7}$ which is probably the consequence of better obstetric and neonatal care. ${ }^{8}$ Coincident with the improved birthweight specific survival rates, an increasing trend in the prevalence of $\mathrm{CP}$ has been reported from several countries. ${ }^{9-13}$

Using a register of cerebral palsy in one health region compiled over several years, we examined the birthweight specific trends in prevalence of cerebral palsy, in association with the changes in pattern of clinical types and attendant functional disabilities according to birthweight group.

\section{Methods}

The register comprises all babies with cerebral palsy born since 1966 to mothers who were resident in the counties of Merseyside and Cheshire at the time of the birth. Compilation of the register began in 1980 so that for the period 1966-79, the data were obtained retrospectively. Among the children with cerebral palsy born in this earlier period, some may have died and their names may have been deleted from the data sources. The number of such cases, however, is likely to be small because the study was notified by the Office of Population, Censuses and Surveys (OPCS) of all deaths in the region where cerebral palsy was mentioned on the death certificate. Multiple data sources were used to compile the register to ensure completeness of ascertainment; these have been described before. ${ }^{2}$ This analysis covers births in the period 1966-89, as ascertainment may be incomplete until about 5 years of age.

Up to and including 1981 , the denominator numbers of live births and neonatal survivors were obtained from returns compiled from statutory birth notifications made to health authorities. The statutory notification returns only provide data for births of $\leq 2500 \mathrm{~g}$; to obtain the numbers of births and deaths of infants weighing $>2500 \mathrm{~g}$ at birth, notification returns of $\leq 2500 \mathrm{~g}$ were subtracted from total birth and death registrations.

Since 1982 the denominator number of live births and neonatal survivors have been obtained from the OPCS records compiled from statutory birth and death registrations.

Denominator birthweight specific data for 1966 were not available. Therefore, 1966 had to be excluded in the analysis of trends in prevalence. There is a minor difference between the denominator birthweight groups provided from the health authorities up to and including 1981 when the groups were $\leq 1500 \mathrm{~g}$, $1501-2500 \mathrm{~g}$, and $>2500 \mathrm{~g}$, and from the OPCS since 1982 when the groups were $<1500 \mathrm{~g}, 1500-2499 \mathrm{~g}$, and $\geq 2500 \mathrm{~g}$. Figure 1, which shows trends in prevalence, uses the health authority birthweight grouping up to and including 1981 and the OPCS grouping from 1982 onwards. Cases weighing exactly 1500 or $2500 \mathrm{~g}$ appear in different birthweight groups in the two time periods.

Up to and including 1981, the denominator number of births was available only as a single entity for $\leq 1500$ g. From 1982 onwards it became possible to split the group into $<1000$ $\mathrm{g}$ and 1000-1499 $\mathrm{g}$. 


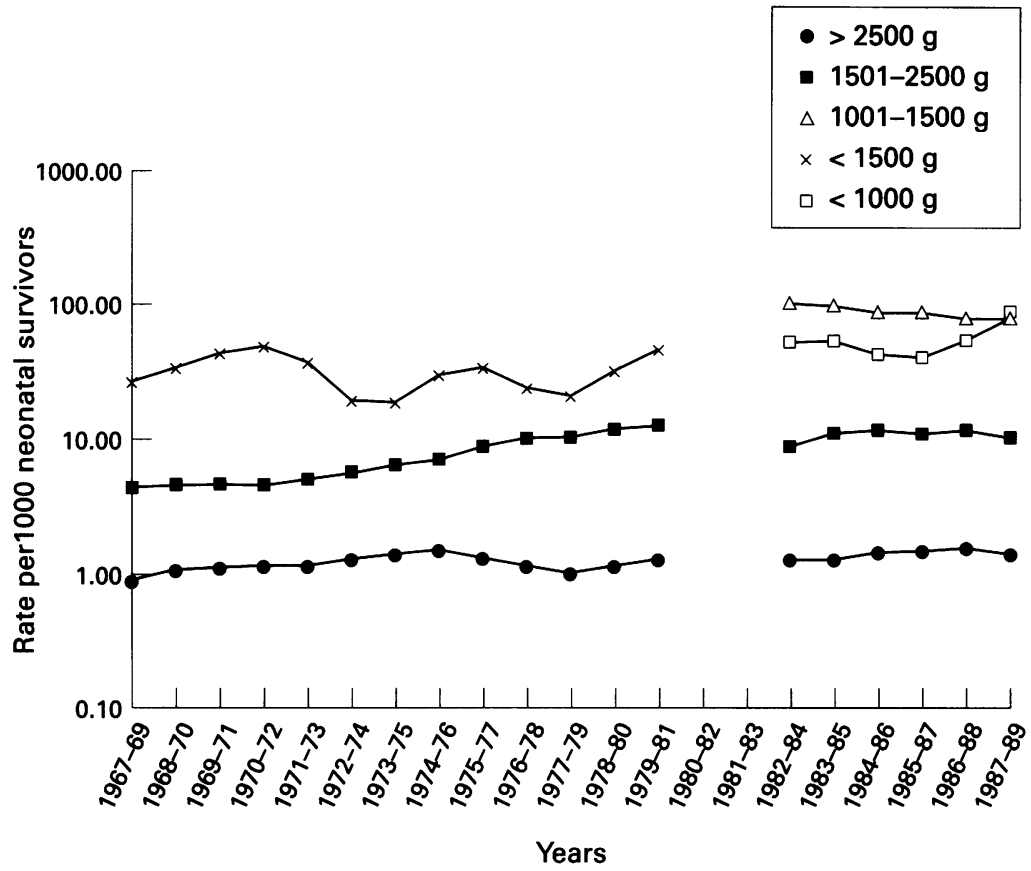

Figure 1 Birthweight specific prevalence of cerebral palsy, Merseyside and Cheshire, 1967-89

Only "idiopathic" cases of cerebral palsy are included in the analysis. "Acquired" cases, when the impairment was considered to have occurred after the 28th day of life, were excluded. If there was uncertainty in the timing of the impairment, the aetiology was presumed to be idiopathic.

In calculating birthweight specific prevalences, the denominator used throughout is the number of neonatal survivors. This is preferable to using the number of live births, particularly in the low birthweight groups where neonatal deaths may make a significant contribution to the denominator. This is
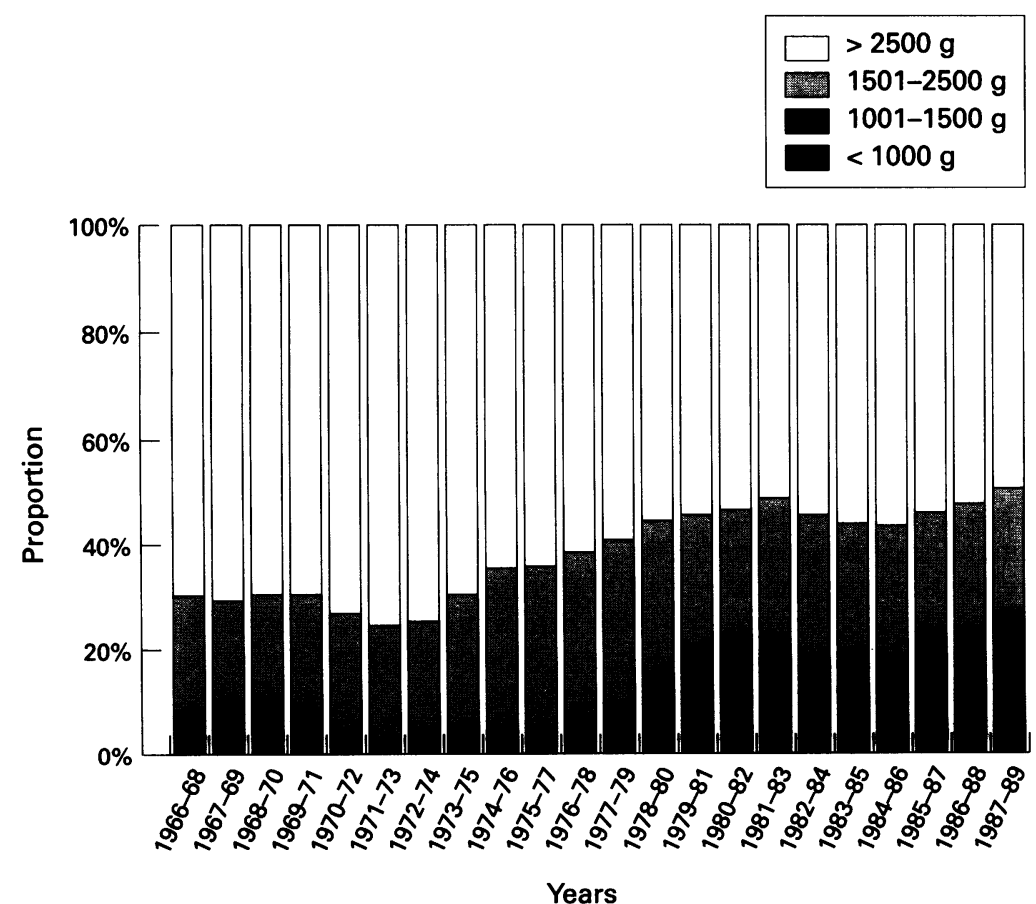

Figure 2 Proportion of cerebral palsy by birthweight groups, Merseyside and Cheshire, 1966-89 (3 year moving averages) further justified because it is rare for cerebral palsy to be diagnosed in the neonatal period.

The clinical type of cerebral palsy was obtained from the paediatric case notes. It was classified as hemiplegia, diplegia, quadriplegia or "other." All mixed cases, where spasticity was associated with dyskinesia or ataxia, were classified according to the type of spasticity. Those designated "other" included the athetoid, ataxic, and dystonic forms without mention of spasticity. When examining the change in the relative proportions in the type of cerebral palsy, the birthweight groups $\leq 1500 \mathrm{~g}$, $1501-2500 \mathrm{~g}$, and $>2500 \mathrm{~g}$ are used for the entire study period-that is, from 1966 to 1989 (fig 2).

Functional disability was categorised for manual dexterity, ambulation, and learning disability. Each of these categories was then classified as "severe" or "not severe." Manual dexterity was considered severely affected if the child could not feed or dress unaided. Ambulation was considered severely compromised if the child was confined to bed or to a wheelchair that was not self propelled. Learning disability was classified as severe if the intelligence quotient (IQ) was $<50$. The assessment of IQ was by a variety of methods and it was impossible to obtain a value from a single standard test procedure that had been applied to all the children. Some children had been assessed on more than one occasion, in which case the most recent IQ score was used.

The statistical test used was $\chi^{2}$ for trends. ${ }^{14}$

\section{Results}

There were 1612 cases of idiopathic cerebral palsy on the register born during 1966-89; 916 were male and 696 female, giving a male:female ratio of 1.3:1.

The clinical type of cerebral palsy was recorded in 1599 cases. These comprised 525 $(32.6 \%)$ cases of hemiplegia, $360(22.3 \%)$ of diplegia, $581(36.0 \%)$ of quadriplegia and $133(8.3 \%)$ "other." There was no record of type of cerebral palsy in $13(0.8 \%)$.

There were $51(3.2 \%)$ cases of birthweight $\leq 1000 \mathrm{~g}, 189(11.7 \%)$ were $1001-1500 \mathrm{~g}, 408$ $(25.3 \%)$ were $1501-2500 \mathrm{~g}$ and $962(59.8 \%)$ were $>2500 \mathrm{~g}$. In two $(0.1 \%)$ cases the birthweight was not recorded.

TRENDS IN BIRTHWEIGHT SPECIFIC PREVALENCE The trends are shown as a three year moving average in fig 1 . The break in the graph is shown because the minor change in birthweight specific grouping was from 1982 onwards and the $\leq 1500$ group could be subdivided into $<1000 \mathrm{~g}$ and $1000-1499 \mathrm{~g}$ from 1982. The trends to 1981 have been published before. $^{2}$

Figure 1 shows that the prevalence of cerebral palsy among infants $>2500 \mathrm{~g}$ has remained steady throughout the period of study at about 1.0-1.4 per 1000 neonatal survivors. In the birthweight group 1500-2499 $\mathrm{g}$ there has been an increase in the prevalence of cerebral palsy from about 4 per 1000 in the late 1960 s to 12 per 1000 neonatal survivors in the late $1970 \mathrm{~s}$-a threefold increase-since when 
Table 1 Change in proportion ( $n$ ) of cerebral palsy by clinical type by birthweight group, 1966-89

\begin{tabular}{llllll}
\hline Birthweight & Clinical type & $1966-71$ & $1972-77$ & $1978-83$ & $1984-89$ \\
\hline$\leq 1500 \mathrm{~g}$ & Hemiplegia & $13 \%(4)$ & $21 \%(3)$ & $26 \%(21)$ & $33 \%(37)$ \\
& Diplegia & $57 \%(17)$ & $50 \%(7)$ & $48 \%(38)$ & $34 \%(39)$ \\
& Quadriplegia & $27 \%(8)$ & $29 \%(4)$ & $25 \%(20)$ & $31 \%(35)$ \\
& Other & $3 \%(1)$ & $0 \%(0)$ & $1 \%(1)$ & $2 \%(2)$ \\
$1501-2500 \mathrm{~g}$ & Hemiplegia & $20 \%(16)$ & $29 \%(24)$ & $30 \%(36)$ & $26 \%(32)$ \\
& Diplegia & $40 \%(31)$ & $33 \%(28)$ & $31 \%(37)$ & $34 \%(42)$ \\
& Quadriplegia & $31 \%(24)$ & $31 \%(26)$ & $36 \%(43)$ & $37 \%(47)$ \\
$>2500 \mathrm{~g}$ & Other & $9 \%(7)$ & $7 \%(6)$ & $2 \%(3)$ & $3 \%(4)$ \\
& Hemiplegia & $30 \%(72)$ & $35 \%(80)$ & $41 \%(91)$ & $42 \%(109)$ \\
& Diplegia & $16 \%(39)$ & $13 \%(29)$ & $11 \%(25)$ & $10 \%(27)$ \\
& Quadriplegia & $43 \%(104)$ & $39 \%(90)$ & $39 \%(87)$ & $36 \%(92)$ \\
& Other & $11 \%(28)$ & $13 \%(31)$ & $9 \%(19)$ & $12 \%(31)$ \\
\hline
\end{tabular}

it has remained constant. The rise in cerebral palsy prevalence among the very low birthweight group, $<1500 \mathrm{~g}$, did not start until the second half of the $1970 \mathrm{~s}$. This birthweight group has also shown a threefold increase from 30 to almost 90 per 1000 neonatal survivors. The subdivision of this birthweight group shows that, during the 1980 s, the prevalence of cerebral palsy remained constant for infants weighing 1000-1499 $\mathrm{g}$ at birth, but for those infants of birthweight $<1000 \mathrm{~g}$, the prevalence has increased. These trends can be summarised as showing that the lower the birthweight group, the later the rise in prevalence of cerebral palsy occurred.

\section{PROPORTION OF CEREBRAL PALSY BY}

BIRTHWEIGHT

Because there has been an increase in prevalence among low birthweight infants but no change in that among those weighing $\geq 2500 \mathrm{~g}$ at birth, the relative proportion that each birthweight group contributes to the total sum of cerebral palsy has altered. The most recent years show that over $50 \%$ of all cerebral palsy cases are of low birthweight $(<2500 \mathrm{~g})$ and that those of birthweight $<1000 \mathrm{~g}$ now make an important contribution to the total (fig 2). In contrast, in the earlier years, low birthweight cases contributed only $30-35 \%$ of the total, while those under $1000 \mathrm{~g}$ were very few.

TREND IN CLINICAL TYPE OF CEREBRAL PALSY To examine the change in the clinical type of cerebral palsy, the 24 year study period has been subdivided into 4 six year periods for each of the birthweight groups $\leq 1500,1501-2500$, and $>2500 \mathrm{~g}$.

The change in clinical type of cerebral palsy according to birthweight group is shown in table 1 . In the birthweight group $\leq 1500 \mathrm{~g}$ there has been a highly significant fall in the proportion of all cerebral palsy that are diplegic from $57 \%$ in $1966-71$ to $34 \%$ in $1984-89$ ( $\chi^{2}$ for trend, $1 \mathrm{df}=5.87 ; \mathrm{P}<0.02)$ and a concomitant increase in hemiplegia from $13 \%$ to $33 \%$.

In the birthweight group 1501-2500 g no striking change in the pattern is seen; the proportion of all cerebral palsy that are quadriplegic increases from $31 \%$ to $37 \%$, but this is not significant.

In the birthweight group $>2500 \mathrm{~g}$ the hemiplegias have increased from $30 \%$ to $42 \%$ of all cerebral palsy cases. This is highly significant ( $\chi^{2}$ for trend $\left.(1 \mathrm{df})=9.93 ; \mathrm{P}<0.002\right)$ with a concomitant fall in diplegias from $16 \%$ to $10 \%$ and in quadriplegias from $43 \%$ to $36 \%$.

\section{TREND IN SEVERITY OF DISABILITY}

Table 2 shows the trends in the proportion of children who were severely disabled in all three functional categories according to birthweight group. In the earliest period of the study, 196671 , in all three functional ability categories, the proportion severely disabled in the normal birthweight group (>2500 g) was about twice that in the lowest birthweight group ( $\leq 1500 \mathrm{~g})$; $38 \%$ vs $23 \%$, respectively, with severe learning disability, $25 \%$ vs $10 \%$ with severe limitation of manual dexterity, and $28 \%$ vs $17 \%$ with severe limitation of ambulation. Those children in the birthweight group 1501-2500 g are intermediate in the proportion who were severely disabled. In the final study quarter, 1984-89, the proportion severely disabled were very similar for all disability categories and birthweight groups. This levelling in the proportion with severe disability has occurred because there has been an increase in severity of disability in the lower birthweight groups but little change in those of normal birthweight.

\section{Discussion}

The two important observations reported here are that the prevalence of cerebral palsy in low birthweight infants is increasing and that this is associated with an increase in the functional severities of the disability. There has also been an increasing proportion of all live births that are of low birthweight. ${ }^{15}$ These changes in the epidemiological pattern of cerebral palsy have implications for the aetiology of the syndrome, on the one hand, and for health and social services provision on the other.

The consistency of the observation that cerebral palsy prevalence among low birthweight infants is increasing in different countries strongly suggests that the trends are real. In part, this has occurred because of recent changes in the case mix of preterm infants,

Table 2 Change in proportion (n) of cerebral palsy by severe functional disability category by birthweight group, 1966-89

\begin{tabular}{llllll}
\hline Functional disability & Birthweight $(g)$ & $1966-71$ & $1972-77$ & $1978-83$ & $1984-89$ \\
\hline Severe learning disability & $\leq 1500$ & $23 \%(7 / 30)$ & $8 \%(1 / 13)$ & $28 \%(212 / 79)$ & $24 \%(24 / 101)$ \\
& $1501-2500$ & $30 \%(23 / 78)$ & $34 \%(28 / 83)$ & $29 \%(34 / 119)$ & $30 \%(36 / 122)$ \\
Severe manual disability & $>2500$ & $38 \%(92 / 241)$ & $41 \%(93 / 229)$ & $33 \%(71 / 214)$ & $32 \%(81 / 250)$ \\
& $\leq 1500$ & $10 \%(3 / 30)$ & $14 \%(2 / 14)$ & $14 \%(11 / 177)$ & $23 \%(26 / 112)$ \\
& $1501-2500$ & $18 \%(14 / 77)$ & $17 \%(14 / 83)$ & $22 \%(26 / 119)$ & $26 \%(32 / 123)$ \\
Severe ambulatory disability & $>2500$ & $25 \%(62 / 244)$ & $28 \%(65 / 233)$ & $23 \%(50 / 216)$ & $26 \%(66 / 256)$ \\
& $\leq 1500$ & $17 \%(5 / 30)$ & $14 \%(2 / 14)$ & $18 \%(14 / 78)$ & $25 \%(28 / 113)$ \\
& $1501-2500$ & $20 \%(16 / 78)$ & $21 \%(18 / 84)$ & $21 \%(25 / 119)$ & $23 \%(28 / 123)$ \\
& $>2500$ & $28 \%(68 / 247)$ & $30 \%(69 / 233)$ & $20 \%(44 / 220)$ & $25 \%(65 / 256)$ \\
\hline
\end{tabular}

Missing data: learning disability $n=53$; manual disability $n=30$; ambulatory disability $n=19$. 
with an increasing number of cases who, previously, would not have been resuscitated (or registered), now receiving intensive care. There has also been a sharp increase in multiple births and the prevalence of cerebral palsy in these births is greater than in singletons.

Because these trends have been associated with improving low birthweight infant survival, there is controversy over whether these can be attributed to better survival of infants in whom the impairment had its origin pre-partum, or whether the impairment occurred peripartum in an infant vulnerable, because of its prematurity, to a failure to maintain physiological homeostasis.

In any consideration of aetiology it is essential to acknowledge that cerebral palsy is not a single disease entity and it is likely that different aetiological factors acting at different times in fetal development are responsible for the complexity of the abnormalities that comprise the syndrome. In many low birthweight infants with cerebral palsy often severe neurological impairments, such as periventricular haemorrhage and leucomalacia, are observed and the disabilities are attributed to these impairments. An alternative explanation, however, is that a fetal brain that is damaged prepartum, may be more vulnerable to physiological insult, leading to periventricular impairments. Endeavours have been made to ascribe relative proportions to pre- and peripartum factors in the aetiology of cerebral palsy. A case control analysis of the Western Australian series attributed about $9 \%$ of the cerebral palsy to an intrapartum initiation of the aetiological pathway. ${ }^{16}$ From Oxford, about one in 10 of those cases of cerebral palsy of gestational age $\geq 37$ weeks showed evidence of intrapartum asphyxia. ${ }^{17}$ In the American National Collaborative Study, $6 \%$ of the cerebral palsy cases were attributed to birth asphyxia. ${ }^{18}$ In contrast, Hagberg attributes a peripartum origin to $52 \%$ of preterm and $21 \%$ of term infants with cerebral palsy. ${ }^{19}$ An even higher proportion, $34 \%$, is attributed to peripartum factors for the bilateral spastic types of cerebral palsy. ${ }^{20}$ These estimates must be viewed with caution because they have been made on the basis of epidemiological data in which it is mandatory that cause and effect are not assumed.

If the increase in prevalence is due to better survival of prepartum impaired infants, further improvements in low birthweight neonatal mortality will lead to increased prevalence of cerebral palsy with an increasing proportion of more severely disabled infants. The changes observed in this study, of increasing severity of disability, are consonant with this hypothesisthat is, as survival rates improve, those who would have died previously because of the severity of the neurological impairment, now survive. Alternatively, if the impairment is peripartum in its timing, with the cerebral palsy attributable to periventricular haemorrhage, parenchymal cystic lesions or leucomalacia, improvements in peripartum clinical management can be expected to reduce the prevalence of cerebral palsy. If this were so, a reduction in cerebral palsy prevalence of the moderately low birthweight infants should, by now, be apparent. No such reduction in prevalence is being observed.

A model could be hypothesised for cerebral palsy of prepartum aetiology:

(i) a prepartum insult impairs fetal neurological development and, either directly, or through a fetal maternal interaction, leads to a reduced gestation and low birthweight;

(ii) there is an interrelation between the severity of the neurological impairment, gestational age (and its proxy of birthweight), and the probability of survival. Thus in normal birthweight infants in whom survival is virtually $100 \%$, all cases of cerebral palsy can be expected to survive and there can be no increase in the prevalence or severity of cerebral palsy. In low birthweight infants, in whom survival rates are still improving, only the more severe cases of cerebral palsy will die. When survival approaches $100 \%$, then both the prevalence and the severity of the cerebral palsy will stabilise;

(iii) as survival in progressively smaller babies improves, so will there be an increase in the prevalence of cerebral palsy among those who survive and an increase in the severity of the disability among those who have cerebral palsy;

(iv) when there is $100 \%$ survival of infants of all gestational ages, the birthweight specific prevalence of cerebral palsy will increase with decreasing birthweight.

Along the same lines, a model of cerebral palsy of peripartum aetiology would hypothesise that:

(i) there will be an initial increase in prevalence of cerebral palsy in each birthweight group and this will be associated with and increase in extent of neurological impairments and severity of disability;

(ii) in each birthweight group, following the initial increase in prevalence, there will a decrease as clinical management techniques improve, and there will be a concomitant decrease in neurological impairments and severity of disability;

(iii) the gestational age (proxy birthweight specific) prevalence of cerebral palsy will become progressively closer in magnitude. It is imperative to recognise that the term cerebral palsy encompasses several disparate specific conditions and that recognition of individual causative factors is likely to come as a result of more sophisticated investigations, such as genetic studies, karyotyping, and biochemical measures. Advances in these areas and the continuing observation of the birthweight specific epidemiology of cerebral palsy will help to determine to what extent the syndrome has a prepartum origin and how much is attributable to peripartum factors.

We are grateful to Children Nationwide, SCOPE, and the regional NHS R\&D committee in its various guises over the years for funding the Mersey Cerebral Palsy register.

1 Stanley F, Alberman E. Birthweight, gestational age and the cerebral palsies. In: Stanley F, Alberman E, eds. The epide- 
miology of the cerebral palsies. Clinics in developmental medicine. No 87. Oxford: Spastics International Medical Publications, 1984:57-68.

2 Pharoah POD, Cooke T, Rosenbloom L, Cooke RWI Effects of birthweight, gestational age, and materna obstetric history on birth prevalence of cerebral palsy. Arch obstetric history on birth pre

3 Pharoah POD, Cooke T, Cooke RWI, Rosenbloom L. Birthweight specific trends in cerebral palsy. Arch Dis Child 1990; 65:602-6.

4 Alberman E. Stillbirths and neonatal mortality in England and Wales by birthweight, 1953-71. Health Trends 1974; 6: 14-17.

5 Pharoah POD, Alberman E. Mortality of low birthweight infants in England and Wales 1953 to 1979. Arch Dis Child 1981 ; 56: 86-9.

6 Alberman E, Botting B. Trends in prevalence and survival of very low birthweight infants, England and Wales: 1983-87. very low birthweight infants, Eng

7 Beuhler JW, Hogue CJR, Zaro S. Postponing or preventing deaths? Trends in infant survival, Georgia, 1974 through 1981. FAMA 1985; 253: 3564-7.

8 Paneth N, Kiely JL, Wallenstein S, Marcus M, Pakter J, Susser M. Newborn intensive care and neonatal mortality in low birthweight infants - a population study. $N$ Engl f Med 1982; 307: 149-55.

9 Hagberg B, Hagberg G, Olow I. The changing panorama of cerebral palsy in Sweden. IV. Epidemiological trends 1959-78. Acta Paediatrica Scandinavica 1984; 73:433-40.

10 Hagberg B, Hagberg G, Olow I,von Wendt $L$ The chang ing panorama of cerebral palsy in Sweden. V. The birth ing panorama of cerebral palsy in Sweden. V. The birth year period $283-90$.
11 Hagberg B, Hagberg G, Olow I. The changing panorama of cerebral palsy in Sweden.VI. Prevalence and origin during the birth year period 1979-86. Acta Paediatrica Scandinavica 1993; 82:387-93.

12 Stanley FJ, Watson L. Trends in perinatal mortality and cerbral palsy in Western Australia, 1967 to 1985. BMF 1992; 304: 1658-62.

13 Dowding V, Barry C. Cerebral palsy: changing patterns of birthweight and gestational age (1976/81). Irish Med f 1988; 88: 25-9.

14 Armitage $P$. Tests for linear trends in proportions and frequencies. Biometrics 1955; 11: 375-86.

15 Pharoah POD, Alberman E. Annual statistical review. Arch Dis Child 1988; 63: 1511-15.

16 Blair E, Stanley F. When can cerebral palsy be prevented? The generation of causal hypotheses by multivariate analysis of a case control study. Paediatr Perinat Epidemiol 1993; 7: 272-301.

17 Gasffney G, Flavell V, Johnson A, Squier M, Sellers S. Cerebral palsy and neonatal encephalopathy. Arch Dis Child 1994; 70: F195-F200.

18 Naeye RL, Peters EC, Bartholomew M, Landis R. Origins of cerebral palsy. Am $\mathcal{F}$ Dis Child 1989; 143: 1154-61

19 Hagberg G. The origins of cerebral palsy. In: David TJ, ed. Recent advances in paediatrics. No 11. Edinburgh: Churchilli Livingstone, 1990: 67-83.

20 Krägeloh-Mann I, Hagberg G, Meisner C, Haas G, Eeg-Olofsson KE, Selbmann HK, et al. Bilateral spasic cerebral palsy - a collaborative study between South-West Germany and Western Sweden. III. Aetiology. Dev Med Child Neurol 1995; 37: 191-203. 